\title{
Perception and utilization of prevention of mother-to- child transmission of human immunodeficiency virus (HIV) services among women living with HIV
}

\author{
Anifat O. Saka ${ }^{1}$, Chiemerigo A. Onyeneho ${ }^{1}$, Chizoma M. Ndikom ${ }^{1}$
}

\begin{abstract}
INTRODUCTION Mother-to-child transmission is the major route of pediatric Human Immunodeficiency Virus (HIV) infection accounting for 90\% of childhood HIV infection. Poor utilization of prevention of mother-to-child transmission (PMTCT) of HIV services has been shown in this situation. Hence, the study assessed the perception and utilization of PMTCT services among Women Living with HIV (WLHIV).

METHODS A cross-sectional research design was used with a purposive sampling technique to select 182 WLHIV within reproductive age attending President's Emergency Plan for Acquired Immunodeficiency Syndrome (AIDS) Relief (PEPFAR)/AIDS Prevention Initiative in Nigeria (APIN) clinic in two secondary Health facilities in Ibadan, Oyo State. A validated structured questionnaire was used for data collection. Descriptive and inferential statistics were used for data analysis.

RESULTS The mean age of the women was $37.0 \pm 6.5$ years. Majority $(74.2 \%)$ of the respondents had good knowledge on PMTCT of HIV, positive perception (89\%) towards PMTCT services while only $42.9 \%$ of the respondents have utilized PMTCT services during pregnancy. However, some of the challenges to use of PMTCT services identified by the respondents were stigma (16.5\%), discrimination (15.4\%), financial constraint (11.5\%) and non-involvement of partner (8.2\%). There was a significant association between level of knowledge and PMTCT services utilization $\left(\chi^{2}=6.244, p=0.012\right)$.

CONCLUSIONS There is need for improvement of knowledge and perception of HIV, MTCT and PMTCT among women through counseling and antenatal education, thereby increasing PMTCT services uptake. Partner involvement, good quality PMTCT services and lack of discrimination of people living with HIV in our society should be encouraged, hence promoting the utilization of PMTCT services.
\end{abstract}

\author{
AFFILIATION \\ 1 Department of Nursing, Faculty \\ of Clinical Sciences, College of \\ Medicine, University of Ibadan, \\ Ibadan, Nigeria
}

\section{CORRESPONDENGE TO \\ Chiemerigo A. Onyeneho. \\ Department of Nursing, Faculty of Clinical Sciences, College of Medicine, University of Ibadan, Oduduwa Road, Oyo State, 200132, Ibadan, Nigeria. E-mail: chiemerigoanne@gmail. com}

\section{KEYWORDS}

HIV, prevention, transmission, utilization, perception, motherto-child

Received: 31 May 2020 Revised: 8 August 2020 Accepted: 23 July 2021

\section{INTRODUCTION}

Human Immunodeficiency Virus (HIV) is currently a major global public health crisis ${ }^{1}$. Although, successes have been recorded in reducing the incidence and mortality of HIV/ AIDS across the globe, the rates of new HIV infections remain disproportionately high across Sub-Saharan Africa, particularly among young women ${ }^{2}$. Sub-Saharan Africa accounts for 9 in 10 of women and children living with $\mathrm{HIV}^{3}$. The rate of mother-to-child transmission (MTCT) of HIV in Nigeria is unacceptably high, accounting for $30 \%$ of the global burden of mother-to-child-transmission of $\mathrm{HIV}^{2}$. In 2017, 220000 children (0-14 years) in Nigeria were living with HIV4. The high burden of MTCT of HIV in Nigeria has been linked with high prevalence of HIV in women of reproductive age and low prevention of MTCT coverage ${ }^{5}$.
MTCT of HIV is the transmission of the virus from mother living with HIV infection to her child during pregnancy, labor, delivery or breastfeeding ${ }^{6}$. These have been identified as major routes accounting for $90 \%$ of childhood HIV infection ${ }^{6}$. PMTCT is a recommended approach for virtual elimination of pediatric HIV to help curb the proportion of MTCT of HIV ${ }^{7}$ and also one of the greatest public health achievements in recent times. The World Health Organization (WHO) promotes a comprehensive approach to PMTCT programs which include preventing new HIV infections among women of childbearing age, preventing unintended pregnancies among women living with HIV (WLHIV), preventing HIV transmission from a woman living with HIV to her baby and providing appropriate treatment, care and support to mothers living with HIV and their children and families ${ }^{5}$. 
Effective PMTCT programs require women and their infants to receive a cascade of interventions or services such as uptake of antenatal services and HIV testing during pregnancy, use of antiretroviral treatment (ART) by pregnant women living with the virus, safe childbirth practices and appropriate infant feeding, uptake of infant HIV testing and other post-natal healthcare services ${ }^{8}$.

Utilization of PMTCT services is a means of reducing the incidence of MTCT of HIV among WLHIV. Studies have reported a link between low incidence of MTCT or possibility of a child contracting HIV from the mother and utilization of PMTCT services ${ }^{9,10}$. PMTCT services are being provided in healthcare institutions across the globe as well as in Nigeria. Despite the provision of these services, there is still poor utilization of PMTCT services ${ }^{11}$.

According to National Agency for Control of AIDS (NACA, 2017), in the first quarter of 2017 only 59010 out of the estimated 246896 children living with HIV in Nigeria were on treatment; among the pregnant women living with HIV, approximately 50000 received antiretroviral drugs to prevent MTCT of HIV, and in mid-2017, antiretroviral treatment coverage was $25 \%$ of children living with HIV. It was also reported that the highest unmet need for PMTCT in Nigeria was in 12 states including Oyo state. The director of NACA (as cited in Daily Trust, 2017) stated that in Oyo state 10000 pregnant women are living with HIV; there are gaps between infected pregnant women and those receiving treatment and about 50 people contract HIV in the state on daily basis. There was also inadequate early infant diagnosis coverage, viral load testing services and weak referral linkage (NACA, 2017) ${ }^{12}$.

Factors that have been associated in the utilization of PMTCT services include knowledge, perception, and accessibility of PMTCT services amongst others. Several studies identified that knowledge and perception about health services are basic factors and determinants of the acceptability of such services ${ }^{13}$. Research has shown that the women's knowledge on PMTCT services, ART and MTCT varied between good and poor $\mathrm{r}^{6,7,9,13,14}$. Women with adequate knowledge of MTCT and PMTCT have been reported to be significant in PMTCT services uptake ${ }^{9,15,16}$ while women with inadequate knowledge of MTCT and PMTCT services were more likely to be ART defaulters ${ }^{9}$. Hence, knowledge of pregnant women on MTCT of HIV has implications for child HIV acquisition ${ }^{6}$. Since previous studies have divergent findings and the studies were not carried out in the study are, there was a need to evaluate the situation in the study area.

Furthermore, the perceptions of people about HIV and MTCT will have an implication in their utilization of PMTCT services. This is supported by some studies which reported that perceptions of women have been linked to the utilization of PMTCT services ${ }^{10}$. Hence, there is a need to assess the knowledge, perception and utilization of PMTCT of HIV services among WLHIV.

The study specific objectives were: to assess women's level of knowledge on prevention of mother to child transmission of HIV; to elicit the women's perception about prevention of mother to child transmission of HIV (PMTCT) programs and services; to investigate the utilization of PMTCT services among HIV infected women; and to identify the perceived challenges to PMTCT services utilization.

\section{METHODS}

A cross-sectional research design was used with a purposive sampling technique to select a sample size of 182 WLHIV within reproductive age. This study was conducted for three months (July 2018 - October 2018). A validated structured questionnaire $(r=0.67)$ was used to collect data on knowledge, perception, utilization and perceived challenges to PMTCT of HIV services from the women attending PEPFAR/APIN clinic in Adeoyo Maternity Teaching Hospital and Saint Mary's Catholic General Hospital, Ibadan, Oyo State. The inclusion criteria were: all the women of reproductive age (15-45 years) living with HIV attending PEPFAR/APIN clinic in Adeoyo maternity teaching hospital and Saint Mary's hospital who were willing to participate. The exclusion criteria were: all the HIV infected women who were not of reproductive age and those who were not willing to participate.

Knowledge of PMTCT services was measured by percentages. Responses were assigned scores Yes $=1$ and $\mathrm{No}=0$. The total obtainable mark was 37. The level of knowledge assessment was divided into sections: good knowledge (18-37 marks) and poor knowledge (1-17 marks). The perception of women about PMTCT of HIV programs and services was analyzed using percentages. The variables were coded as follows: strongly agree $=5$, agree $=4$, undecided $=3$, disagree $=2$ and strongly disagree $=1$. The total obtainable score was 70. The level of perception assessment was divided into sections: positive perception (45-70 marks) and negative perception (1-44 marks). Utilization of PMTCT service which is integrated into the usual monitoring of pregnant women is measured with the option of Yes or No to the question of ever utilized the services. If a pregnant woman tests positive to HIV and continues with follow-up care it means she is utilizing the services but if she does not comply then it is a non-utilization.

Ethical approval was obtained from UI/UCH Institutional Review Board. Ethical principles were observed. Participants were given a brief and clear introduction on the purpose of the study which is to address their perceptions and utilization of PMTCT services and their consent was obtained. They were assured that confidentiality and anonymity was maintained by informing the respondents that their names should not be included on the questionnaires given to them. They were also given information on the average duration of time required to fill in the questionnaire and the fact that they were free to discontinue at any time.

Data were analyzed using both descriptive (mean, percentages and frequencies) and inferential statistics (chisquared) at $5 \%$ level of significance.

\section{RESULTS}

The mean age of the respondents was $37.0 \pm 6.5$ years, the majority (162; 89\%) of the respondents were married, 
Figure 1. Respondents' level of knowledge, perception and uptake of PMTCT services

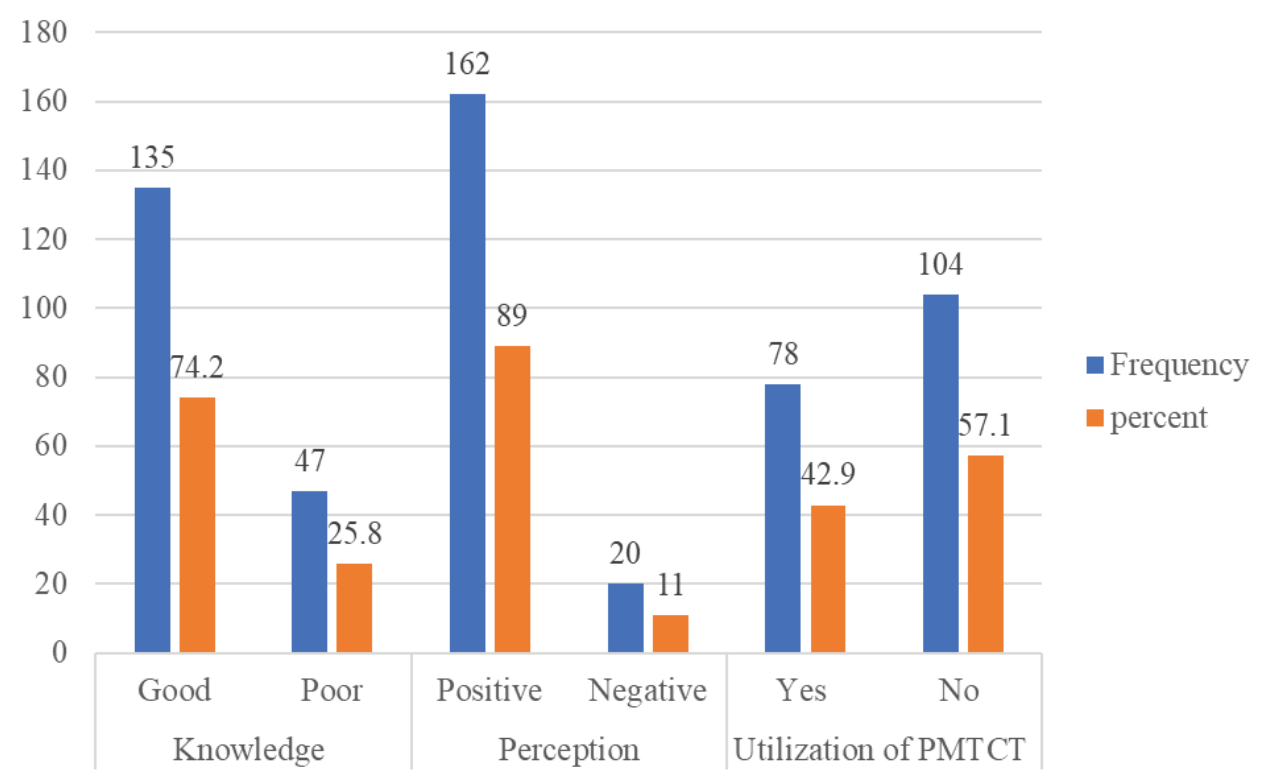

168 (92.3\%) were of Yoruba ethnic group and 151 (83\%) were self-employed while many 99 (54.4\%) were Muslims (Supplementary Table 1). Figure 1 indicates that the majority (135; 74.2\%) had good knowledge on PMTCT of HIV, with a mean score of $24.27 \pm 10.1$. The majority (162; $89 \%$ ) of the respondents had positive perception about PMTCT services.

The mean score for perception about PMTCT services was 52.15 \pm 9.64 . A few respondents identified discrimination (15.4\%), financial constraint (11.5\%), poor quality of PMTCT services (6.6\%) and non-involvement of partner (8.2\%) as

Table 1. Perceived challenges to PMTCT program and services, and factors associated with non-utilization of PMTCT service

\begin{tabular}{|c|c|}
\hline & $n(\%)$ \\
\hline \multicolumn{2}{|c|}{ Perceived challenges to PMTCT program and services } \\
\hline Stigma & $30(16.5)$ \\
\hline Discrimination & $28(15.4)$ \\
\hline Financial constraints & $21(11.5)$ \\
\hline Poor quality of PMTCT services & $12(6.6)$ \\
\hline Role of traditional birth attendants & $7(3.8)$ \\
\hline Non-involvement of partner & $15(8.2)$ \\
\hline Socioeconomic status & $7(3.8)$ \\
\hline \multicolumn{2}{|c|}{ Perceived factors with РMTCT service utilization } \\
\hline Mother's age & $9(4.9)$ \\
\hline Occupational status & $13(7.1)$ \\
\hline Partner's educational level & $7(3.8)$ \\
\hline Partner's HIV status & $6(3.3)$ \\
\hline Having discussions with partner & $4(2.2)$ \\
\hline Satisfaction with the service & $12(6.6)$ \\
\hline
\end{tabular}

Table 2. There is no significant association between selected sociodemographic variables and utilization of PMTCT service

\begin{tabular}{|c|c|c|c|c|c|c|}
\hline \multirow[t]{2}{*}{ Variables } & \multicolumn{6}{|c|}{ Utilization of PMTCT services } \\
\hline & Yes & No & Total & $\chi^{2}$ & $d f$ & $p$ \\
\hline \multicolumn{7}{|l|}{ Age (years) } \\
\hline $18-24$ & 4 & 4 & 8 & 38.504 & 3 & 0.054 \\
\hline $25-31$ & 12 & 15 & 27 & & & \\
\hline $32-38$ & 35 & 26 & 61 & & & \\
\hline $39-45$ & 27 & 59 & 86 & & & \\
\hline \multicolumn{7}{|l|}{ Occupation } \\
\hline Unemployed & 61 & 92 & 153 & 4.154 & 2 & 0.125 \\
\hline Employed & 17 & 12 & 29 & & & \\
\hline \multicolumn{7}{|l|}{ Marital status } \\
\hline Single & 3 & 8 & 11 & 8.623 & 2 & 0.013 \\
\hline Married & 75 & 87 & 162 & & & \\
\hline Separated & 0 & 9 & 9 & & & \\
\hline \multicolumn{7}{|l|}{ Religion } \\
\hline Christianity & 37 & 46 & 83 & 0.185 & 1 & 0.667 \\
\hline Islam & 41 & 58 & 99 & & & \\
\hline \multicolumn{7}{|l|}{ Educational level } \\
\hline No formal education & 4 & 5 & 9 & 0.590 & 3 & 0.899 \\
\hline Primary & 20 & 32 & 52 & & & \\
\hline Secondary & 44 & 54 & 98 & & & \\
\hline Tertiary/university & 10 & 13 & 23 & & & \\
\hline \multicolumn{7}{|l|}{$\begin{array}{l}\text { Number of } \\
\text { pregnancies }\end{array}$} \\
\hline$<4$ & 67 & 81 & 148 & 6.702 & 2 & 0.569 \\
\hline$>5$ & 10 & 13 & 23 & & & \\
\hline None & 1 & 10 & 11 & & & \\
\hline
\end{tabular}


Table 3. Association between utilization of PMTCT services and perceived challenges to PMTCT services

\begin{tabular}{|l|c|c|c|c|c|}
\hline \multirow{2}{*}{ Perceived challenges } & \multicolumn{6}{c}{ Utilization of PMTCT services } \\
\hline & Yes & No & $\chi^{2}$ & $\boldsymbol{d} f$ & $\boldsymbol{p}$ \\
\hline Stigma & & & 0.421 & 2 & 0.810 \\
\hline Yes & 23 & 30 & & & \\
\hline No & 55 & 72 & & & \\
\hline Discrimination & & & 0.392 & 2 & 0.822 \\
\hline Yes & 22 & 28 & & & \\
\hline No & 56 & 74 & & & \\
\hline Financial constraints & & & 3.943 & 2 & 0.139 \\
\hline Yes & 26 & 21 & & & \\
\hline No & 52 & 81 & & & \\
\hline $\begin{array}{l}\text { Poor quality of PMTCT } \\
\text { services }\end{array}$ & & & 0.187 & 2 & 0.911 \\
\hline Yes & 12 & 15 & & & \\
\hline No & 66 & 87 & & & \\
\hline Non-involvement of & & & 3.202 & 2 & 0.202 \\
\hline partner & & & & & \\
\hline Yes & 5 & 72 & & & \\
\hline No & 15 & 87 & & & \\
\hline Socioeconomic factors & & & 0.636 & 2 & 0.728 \\
\hline Yes & 8 & 70 & & & \\
\hline No & 7 & 92 & & & \\
\hline
\end{tabular}

perceived challenges to non-utilization of PMTCT services. Also, a few of the respondents identified age of mothers (4.9\%), occupational status (7.1\%), partner's educational status (3.8\%), partner's HIV status (3.3\%), having discussion with partners (2.2\%) and client's satisfaction with the service (6.6\%) as factors associated with nonutilization of PMTCT service (Table 1). Only $42.9 \%$ of the respondents had utilized PMTCT services during pregnancy. Hypotheses testing showed that that there is a significant association between level of knowledge and utilization of PMTCT services $(p=0.012)$, and knowledge with marital status (Tables 2 and 3 )

\section{DIscussion}

PMTCT of HIV services is one of the ways to reduce MTCT of HIV. The findings from this study have shown that respondents demonstrated good knowledge on PMTCT of HIV. This corroborates the findings from similar studies, which revealed that participants in their study had good knowledge of PMTCT services ${ }^{1,9,17}$. However, in contrast to these findings, some studies reported inadequate knowledge of PMTCT of HIV ${ }^{6,14}$. It could be inferred that the good knowledge of PMTCT reported by these women can be associated with the education level of the women as most had secondary and tertiary education. Research has further supported this evidence that educational level and counseling during antenatal periods have aided in improving the knowledge of women on PMTCT services ${ }^{6,9,18}$. Hence, there is a need to improve the knowledge level of women during antenatal clinics through education of PMTCT services and its importance. This will assist in promoting the utilization of the services.

This study revealed that generally, the women had positive perception about PMTCT services. In contrast, a similar study has shown that some respondents have a negative perception towards PMTCT services as they believe the issue is spiritual and needs spiritual intervention?. The way an individual perceives his or her health or certain health services or health seeking behaviors will determine to what extent the person is willing to seek or utilize healthcare. This is supported by the Health Belief Model which states that a person's belief in a personal threat of an illness or disease together with a person's belief in the effectiveness of the recommended health behavior or action will predict the likelihood that the person will adopt the behaviour $^{19}$. This can be applied in the way PMTCT services are utilized by women living with HIV. The extent women living with HIV perceive PMTCT services as being beneficial or not will determine their willingness to seek and utilize the services. A positive perception towards PMTCT will enhance the utilization of PMTCT services whereas a negative perception will hinder the utilization of PMTCT services. This corroborates the findings of some studies which reported that perception has been associated in the utilization of PMTCT services ${ }^{9}$. It is important that beliefs and several factors that are associated in negative perception of PMTCT services, be dispelled through awareness, education, in order for women to seek PMTCT services.

Furthermore, findings from this study have shown low utilization of PMTCT services during pregnancy. One may think that since the women have good knowledge and positive perception towards PMTCT services, the utilization of PMTCT services amongst these women will be higher, however, only a small percentage utilized these services. A chi-squared test done to ascertain if there is an association between knowledge level and utilization of PMTCT services revealed a significant result. Hence, it is imperative to say that knowledge level is significant in the utilization of PMTCT services. This corroborates the findings of similar studies which showed that knowledge level and educational level had impact on the utilization of PMTCT services ${ }^{9,15}$. Also, perception of PMTCT services has been linked to utilization of the services ${ }^{9}$. Hence, there is a need to dispel negative perceptions amongst participants who have negative perception of PMTCT services in order to enhance the utilization of these services. This can be ensured by counseling and education during antenatal clinics and education through religious leaders on the causes of HIV and its prevention.

Also, certain perceived challenges have been shown in this study to be associated with the utilization of PMTCT services and they are stigma, discrimination, financial constraints, unawareness of HIV seropositive services and poor quality services. This is in agreement with findings of a similar study ${ }^{11}$. The implication of this is that if these 
challenges are not met, it will lead to low utilization of PMTCT services. Hence, there is a need to find measures to remove these factors, which can be achieved through making the services affordable for the people by government, improving the quality of services, creating awareness to the public on the negative implication of stigmatization and discrimination on the health of these women.

There is also a need to carry out further research to evaluate the effectiveness of PMTCT services in the reduction of mother-to-child-transmission in the facilities, and to compare the perception and utilization PMTCT services of women in urban centers and those resident in rural centers. Exploration of factors influencing utilization PMTCT through a qualitative study will be valuable.

\section{CONCLUSIONS}

Findings suggest there is a need for improvement of knowledge and perception of HIV, MTCT and PMTCT among women through counseling and antenatal education, thereby increasing PMTCT services uptake. Partner involvement, good quality PMTCT services and lack of discrimination of people living with HIV should be encouraged, will help to promote the utilization of PMTCT services.

\section{REFERENGES}

1. Mamudu RA. Knowledge Attitude and Practices of Prevention of Mother to Child Transmission of HIV(PMTCT) among women of Child Bearing Age, in Karu Village, Abuja, Nigeria. Master Thesis. Stellenbosch University, 2014. Accessed August 8, 2020. https:// scholar.sun.ac.za/handle/10019.1/86249

2. Arisegi S, Awosan KJ, Abdulsamad H, Adamu AH, Isah MB, Mora S. Knowledge and Practices Regarding Prevention of Mother-to-child Transmission of HIV among Health Workers in Primary Healthcare Centers in Sokoto, Nigeria. Int STD Res Rev. 2017;6(3):1-9. doi:10.9734/ISRR/2017/38680

3. UNICEF. CHILDREN AND AIDS: Statistical Update. UNICEF, 2017. Accessed August 8, 2020. https://data. unicef.org/wp-content/uploads/2017/11/HIVAIDSStatistical-Update-2017.pdf

4. Nigeria - People living with HIV receiving ART - as of 30 June (\#) - Total. 2018. knoema.com. Accessed August 8, 2020. https://knoema.com/UNAIDSINF02018/ united-nations-aidsinfo-statistics?

5. National AIDS and STI's Control Programme. National guidelines for HIV prevention, treatment, and care. Nigeria Federal Ministry of Health; 2016;11-118. Accessed August 8, 2020. https://www.researchgate. net/publication/319873085_2016_NATIONAL_ GUIDELINES_FOR_HIV_PREVENTION_TREATMENT_ AND_CARE_NATIONAL_AIDS_AND_STIS_CONTROL_ PROGRAMME_FEDERAL_MINISTRY_OF_HEALTH_ NIGERIA

6. Birhane T, Assefa Tessema G, Addis Alene K, Dadi AF. Knowledge of pregnant women on motherto-child transmission of HIV in Meket District, Northeast Ethiopia. J Pregnancy. 2015;(960830):1-6.

\section{doi:10.1155/2015/960830}

7. Falnes EF, Tylleskär T, de Paoli MM, Manongi R, Engebretsen IM. Mothers' knowledge and utilization of prevention of mother to child transmission services in northern Tanzania. J Int AIDS Soc. 2010;13(1):36. doi:10.1186/1758-2652-13-36

8. Feyera A, Megerssa B, Legesse D, Hailemichael F. Prevention of mother to child transmission of HIV/ AIDS: Service utilization and associated factors among selected public health facilities in Ethiopia. Academic Journal. 2017;8(1):1-13. doi:10.5897/MPR2017.0132

9. Boateng D, Kwapong GD, Agyei-Baffour P. Knowledge, perception about antiretroviral therapy (ART) and prevention of mother-to-child-transmission (PMTCT) and adherence to ART among HIV positive women in the Ashanti Region, Ghana: a cross-sectional study. BMC Womens Health. 2013;13(2):1-8. doi:10.1186/1472-6874-13-2

10. Sitohang MY. Utilization Factors of Prevention Mother to Child HIV Transmission (PMTCT) Program Among Pregnant Women. Journal of Indonesian social sciences and humanities. 2017;7(2):107-118. doi:10.14203jissh.v7i2.144

11. Anígilájé EA, Ageda BR, Nweke NO. Barriers to uptake of prevention of mother-to-child transmission of HIV services among mothers of vertically infected HIVseropositive infants in Makurdi, Nigeria. Patient Prefer Adherence. 2016;10:57-72. doi:10.2147/PPA.S87228

12. FACT SHEET: Prevention of Mother to Child Transmission (PMTCT), 2016. National Agency for the Control of AIDS (NACA). Accessed February 28, 2018.

https://web.archive.org/web/20210117215643/https:// naca.gov.ng/fact-sheet-prevention-mother-childtransmission-pmtct-2016/

13. Balogun FM, Owoaje ET. Perception about the 'Opt Out Strategy' for HIV Testing and Counselling among Pregnant Women attending Antenatal Clinic in Ibadan, Nigeria. Journal of Community Medicine and Primary Health Care. 2016;28(1):45-51. Accessed August 8, 2020. https://www.ajol.info/index.php/jcmphc/ article/view/139406

14. Sama CB, Feteh VF, Tindong M, Tanyi JT, Bihle NM, Angwafo FF. Prevalence of maternal HIV infection and knowledge on mother-to-child transmission of HIV and its prevention among antenatal care attendees in a rural area in northwest Cameroon. PLoS One. 2017;12(2):e0172102. doi:10.1371/journal.pone.0172102

15. Duff P, Kipp W, Wild TC, Rubaale T, Okech-Ojony J. Barriers to accessing highly active antiretroviral therapy by HIV-positive women attending an antenatal clinic in a regional hospital in western Uganda. J Int AIDS Soc. 2010;13(1):37. doi:10.1186/1758-2652-13-37

16. Olowokere AE, Adelakun OA, Komolafe AO. Knowledge, perception, access and utilisation of HIV counselling and testing among pregnant women in rural communities of Osogbo town, Nigeria. Aust $J$ Rural Health. 2018;26(1):33-41. doi:10.1111/ajr.12368

17. Umeobika JC, Ezebialu IU, Ezenyeaku CT, Ikeako LC. Knowledge and perception of mother to child 
transmission of human immunodeficiency virus among South Eastern Nigerian pregnant women. Journal of HIV and human reproduction. 2013;1(1):15-19. Accessed August 8, 2020. http://www.j-hhr.org/text. asp?2013/1/1/15/116536

18. Ojong IN, Unachukwu SU, Ita RE. Knowledge of Prevention of Mother to Child Transmission of HIV/Aids among Women of Child Bearing Age in Secondary Health Facility in Calabar, Cross River State, Nigeria. IOSR Journal of Nursing and Health Science. 2016;5(6):1-6. doi:10.9790/1959-0506060106

19. LaMorte WW. Behavioural Change Model. Boston University School of Public Health; 2019. Updated September 9, 2019. Accessed August 8, 2020. https://sphweb.bumc.bu.edu/otlt/MPH-Modules/SB/ BehavioralChangeTheories/index.html

\section{CONFLICTS OF INTEREST}

The authors have completed and submitted the ICMJE Form for Disclosure of Potential Conflicts of Interest and none was reported.

\section{FUNDING}

The research work was funded solely by the researchers. No extra source of funding was received for this study.

\section{ETHICAL APPROVAL AND INFORMED CONSENT}

Ethical approval was obtained from UI/UCH Institutional Review Board. Participants' informed consent was obtained.

\section{DATA AVAILABILITY}

The data supporting this research cannot be made available for privacy reasons.

\section{PROVENANGE AND PEER REVIEW}

Not commissioned; externally peer reviewed. 